\title{
A importância interdisciplinar da documentação da Justiça Eclesiástica em São Paulo: o caso Joana Gil
}

DOI: http://dx.doi.org/10.21165/el.v49i1.2697

\section{Nathalia Reis Fernandes ${ }^{1}$}

\section{Resumo}

Este estudo visa indicar as peculiaridades de um dos documentos manuscritos constantes do fundo documental da Cúria Metropolitana de São Paulo, dentre aqueles que se ocupam dos processos e procedimentos ligados aos chamados crimes contra a Igreja, os quais tramitavam perante a Justiça Eclesiástica. Com isso, pretende-se circunscrever o panorama dos estudos que vêm sendo desenvolvidos pelo projeto Bruxas Paulistas, por meio de um exemplo do material estudado. Serão descritos, do ponto de vista codicológico e das circunstâncias do caso, os autos da denúncia feita contra Joana Gil, jovem oriunda da cidade de Mogi Mirim, conhecida em razão de práticas da ordem do maravilhoso ou sobrenatural. Também serão expostas algumas peculiaridades linguísticas e jurídicas que podem fundamentar trabalhos futuros com viés interdisciplinar, vinculando a filologia, a linguística e o direito.

Palavras-chave: Justiça Eclesiástica; Bruxas Paulistas; crimes contra a Igreja; feitiçaria; edição de manuscritos.

1 Sem filiação institucional; nathlet@gmail.com; http://orcid.org/0000-0002-1862-7835. 


\title{
The interdisciplinary importance of Ecclesiastical Court's documentation in São Paulo: the Joana Gil case
}

\begin{abstract}
This study aims to indicate some peculiarities of one of the manuscript documents included in the documentary background of the Metropolitan Curia of São Paulo, among those that deal with procedures and claims related to the so-called crimes against the Church, which were held before the Ecclesiastical Court. Thus, it is intended to show the status of the studies that have been developed by Bruxas Paulistas project, through an example of that material. From the codicological point of view and the circumstances of the case, there will be a description of the accusation made against Joana Gil, a young woman from Mogi-Mirim, Brazil, who was famed for marvelous or supernatural practices. There will also be an exposition on some linguistic and legal peculiarities that can support future work with focus on interdisciplinary studies, by linking philology, linguistics, and law.
\end{abstract}

Keywords: Ecclesiastical Court, Bruxas Paulistas, crimes against the Church, witchcraft, manuscript edition.

\section{Introdução}

O projeto Bruxas Paulistas, coordenado pelo Prof. Marcelo Módolo junto à Faculdade de Filosofia, Letras e Ciências Humanas da Universidade de São Paulo, tem recuperado documentação pertinente a processos e procedimentos judiciais que tramitaram junto à Justiça Eclesiástica. A documentação, pertencente à Cúria Metropolitana de São Paulo, revela uma faceta esquecida da história do país: a presença, ainda que discreta, da Inquisição no Brasil e a forma pela qual a religião católica tratava usos e costumes de outros povos, bem como fenômenos tidos como "sobrenaturais".

Os arquivos da Cúria, cuidadosamente organizados e preservados pela ação diligente de seu diretor, Jair Mongelli Junior, acolheram a proposta do projeto e abriram as portas para essa documentação de imensa riqueza para o pesquisador.

Foram localizados doze documentos junto à Cúria, que consistem em investigações a respeito de atos religiosos fora do costume católico e de fatos sobrenaturais, tidos como feitiçaria e punidos pela lei então vigente como crime contra a Igreja.

Esses documentos trazem algumas particularidades filológicas, que tornam interessante sua exploração e reforçam a importância da recuperação dos arquivos da Igreja Católica, em especial, os relacionados à Cúria, bem como trazem informações importantes para a própria história brasileira, e, mais especificamente, do direito brasileiro. 
Além disso, procura-se acostumar o olhar do filólogo às estruturas judiciais, algo que já vem sendo explorado por vários pesquisadores e que, de nossa parte, vem sendo estudado desde o mestrado (FERNANDES, 2012).

Este trabalho é fruto do levantamento feito pelo Projeto até agora. Mas, aqui, nosso foco será a exploração dos aspectos filológicos e históricos que podem contribuir para a compreensão desse tipo de documentação, a partir da investigação conduzida em face das jovens Joana e Lucrécia Gil na cidade de Mogi Mirim (SP), por suposta prática de feitiçaria.

A partir desses aspectos, buscaremos comprovar a importância da documentação, que é bastante reforçada por dar margem a abordagens possíveis em diversas áreas do conhecimento: não só a filologia, evidentemente, mas também a linguística diacrônica e a história do direito. E é isso que tentaremos comprovar nos itens a seguir.

\section{A documentação estudada}

\subsection{Análise codicológica}

Partindo dos pressupostos sugeridos por Cambraia (2005) para a descrição documental, passamos a descrever a documentação objeto do estudo.

Trata-se de material elaborado ao longo do ano de 1758, na cidade de Mogi Mirim (SP), apresentado por folha de rosto preparada pelo próprio Arquivo da Cúria, em papel pautado e com observações a mão (neste ponto, o punho é do próprio Jair Mongelli). Esse papel, no formato folha de almaço, acaba servindo como uma "encadernação" improvisada para os catorze fólios originais. O procedimento é repetido nos demais documentos que compõem o fundo da Justiça Eclesiástica na Cúria.

O suporte material dos documentos originais é cartáceo, sem pauta, apoiado em papel de arroz pelo Arquivo para conservação (o papel original está carcomido por traças em diversos pontos). O papel é de gramatura e cor equivalentes aos de outros documentos do mesmo fundo da Justiça Eclesiástica; e isso é bastante interessante, já que os diversos processos e procedimentos investigativos são de diversas partes do Estado talvez estejamos diante de um padrão de papel utilizado na época ou na própria Justiça Eclesiástica (contudo, até o momento, isso não passa de conjectura).

A mancha é ocupada de forma regular, quase uniforme, com pouquíssimas variações nesse sentido. A tinta é escura, possivelmente ferrogálica. 
No manuscrito ora estudado, quatro punhos estão presentes: o primeiro deles, Manoel Paez Gracia (Garcia?) é o mais constante, pois era o escrivão encarregado de captar os testemunhos que fazem parte da investigação. Mas Antonio Xavier de Mattos, vigário de Mogi Mirim e responsável pela abertura da investigação, também participa. Quando os autos ${ }^{2}$ são enviados para a Cúria de São Paulo, em fase posterior do procedimento, passam a participar os punhos do escrivão Pedro Campos da Nóbrega Nogueira e do bispo da Sé, Manoel José Vaz.

O material que levantamos junto à Cúria data do século XVIII e se restringe ao Estado de São Paulo; portanto, nada mais natural que algum punho se repita em algum momento. Especificamente em relação à documentação estudada neste momento, Manoel José Vaz já participara da investigação conduzida em Jundiaí em face de Escholastica Pinta da Silva e sua mãe, também acusadas de feitiçaria (esta documentação foi analisada em Porto (2018), estudo também derivado do projeto Bruxas Paulistas).

\subsection{0 caso}

A documentação traz um auto em que o escrivão Gracia, incorporando também o papel de promotor eclesiástico, dá início a uma investigação, acerca de fato relatado ao Padre Mattos por um certo Manoel Gil: sua sobrinha Joana havia produzido feitos sobrenaturais em sua casa enquanto dormia - imagens sacras se deslocaram até sua cama enquanto dormia e chegaram mesmo a exalar sangue. Joana também havia vaticinado sobre a cidade e seus habitantes ${ }^{3}$.

(01) em Sua caza acontecia hum milagre extraordinario, qual era, de noyte, passarem-se as Imagens de Seo Oratorio, a da Virgem Nossa Senhora do Rozario com seo Menino nos brassos, e mais a de IESV Christo Crucificado, desde o Lugar em que estavão, para a cama onde dormia sua sobrinha [...], por virtude sobrenatural, sem que pessoa az Levasse, e ali se Colocarão sobre o peyto da mesma Denunciada e lhe revellarão successos ocultos futuros como estas para vir um grande castigo de Deos sobre a Freguesia (fólio 12 r).

Suspeita-se que Lucrécia, filha de Manoel e prima de Joana, teria criado toda a cena do deslocamento das imagens, como brincadeira. A própria condição de Joana, "bastarda"

2 Autos: no jargão forense, o "conjunto das peças que compõem um processo judicial" (SIDOU, 2016, p. 138) ou outros procedimentos de fundo judicial, como os inquéritos. No singular, a palavra se vincula ao sentido latino original de ação ou movimento necessário, uma narrativa de medida ou ato processual (idem, ibidem).

3 Os trechos selecionados abaixo são todos do testemunho do Padre Mattos, que é bastante detalhado em comparação aos demais. Os fatos são relatados de acordo com o que Manoel Gil Ihe diz em consulta sobre o suposto "milagre" da sobrinha, assim como com as decisões que ele, Padre Mattos, tomou a respeito do caso. 
e "gentia da terra" (isto é, mestiça de indígena e branco), serve, para o Padre Mattos, como forma de avaliar o caráter da moça e a provável mentira. Mas as duas denunciadas rechaçam a acusação.

(02) Em Ocurrencia decazo tal, avaliando-o por invenção, e arteficio, ou material, ou diabolico, pelas circunstancias de Ser mulher bastarda, isso he; de mistura de branco e carrijo, e rustica (fólio $11 \mathrm{v}$ ).

O Padre Mattos, em vista disso, determina a Manoel que punisse as moças com açoites, devendo continuar a fazê-lo caso os fenômenos continuassem; também determina a oitiva de testemunhas e diz a Manoel que não divulgue a ocorrência. Porém, os eventos fantásticos não param, mesmo depois do castigo.

(03) Assim prometeo cumprir o dito Manoel Antonio, e com effeyto (me contou) castigara a ambas denunsiadas; de que Rezultou aparecerem no outro dia, ao amanhecer, as mesmas Imagenz Sacrilegamente afeadaz, e pollatas com Sangue Corrupto, de cor negra, e com ferida, assim em Seos labios (fólio $11 \mathrm{v}$ ).

Os autos registram que Joana não aprecia as "manifestações". Considerava-as "coisa do demônio". Porém, quem nos informa isso é o Padre Mattos, que teria ouvido a própria Joana dizê-lo.

(04) E Só me aprezentou a Sobrinha denunsiada, que perguntada pelo facto, me respondeo, não ella Senão que o demonio obrára tudo aquillo: e logo a fez levar, não para caza do dito Tio, onde estava, Senaõ para a de Seo Pay; e Se Sobreviveraõ os milagres: depois ouvi dizer, que ella Denunsiada contava; que em forma de Rapaz Etiope via obrar o Demonio aquelas diabruras (fólio 12 r).

Mas não há registro feito a partir das palavras proferidas por Joana perante o escrivão, nem tampouco de sua prima Lucrécia.

Coletados os testemunhos - que corroboram alguns dos fatos relatados por Manoel -, os autos são enviados a São Paulo para análise da Cúria central, que decide enviar a documentação ao Tribunal do Santo Ofício, sediado em Portugal. Porém, não há notícia da conclusão a que chegou o Tribunal a esse respeito. Se consideradas culpadas, as moças poderiam ser levadas a Portugal para julgamento, e sujeitas às penas pertinentes. 


\section{Entendendo a documentação}

\subsection{Justiça Eclesiástica}

Como mencionado anteriormente, a documentação em questão compõe os autos de um procedimento em curso perante a Justiça Eclesiástica de São Paulo, órgão vinculado ao Tribunal da Inquisição/Congregação do Santo Ofício.

A Justiça Eclesiástica era a competente 4 para o julgamento de questões de fé e costumes e tudo que fosse contrário à Igreja, conforme previsão das Ordenações Filipinas compêndio legal elaborado por determinação de Filipe ll da Espanha, quando este soberano passou a reinar por toda a Península Ibérica (como Filipe I de Portugal). As Ordenações só entraram em vigor no reinado de seu sucessor, mas perduraram por longo tempo, mesmo depois da restauração da monarquia portuguesa; no Brasil, especificamente, permaneceram em vigor mesmo depois da Independência, e aos poucos foram sendo substituídas (TUCCl; AZEVEDO, 2009).

O Livro IV das Ordenações Filipinas regula a parte estritamente procedimental dos feitos em andamento na Justiça Eclesiástica, como a própria questão da competência e da execução das penas. Já o Livro $\vee$ traz o rol dos crimes por violação à fé católica e o funcionamento da Justiça Eclesiástica em Portugal (e, por extensão, no Brasil, na época colônia portuguesa). Porém, não houve o estabelecimento do Santo Ofício por aqui; sua presença se limitava à visitação esparsa de inquisidores.

Entre outros crimes contra a fé, a Justiça Eclesiástica investigava os crimes de blasfêmia, feitiçaria e heresia. Curiosamente, a conversão do cristão em outro credo religioso era objeto de análise pela Justiça dita "comum", secular.

A Justiça Eclesiástica se limitava a investigar o crime (em nível local, como ocorre no documento aqui analisado), com o juiz eclesiástico funcionando como uma espécie de "perito" que avalia a existência da ofensa à religião. A sentença, com a determinação da pena a ser aplicada, era da competência do Tribunal do Santo Ofício. Porém, a execução da pena ficava por conta da justiça secular, que, em tese, deveria reavaliar a pena eclesiástica, mas na prática limitava-se à execução pura e simples (ALMEIDA, 1870, Livro $\checkmark$ das Ordenações, ).

4 Competência: grau ou delimitação da manifestação da jurisdição, ou seja, a atividade em que o Poder Judiciário "diz o direito" em meio a conflitos de interesse (SIDOU, 2016). É a "quantidade de jurisdição cujo exercício é atribuído a cada órgão ou grupo de órgãos" (CINTRA; GRINOVER; DINAMARCO, 1998, p. 229, citando LIEBMAN). 
As penas aplicáveis variavam entre o pagamento de determinada quantia e a morte, passando pelo confisco de bens, de acordo com o crime verificado. Aos crimes mais graves era aplicada uma "pena corporal", em que o cadáver era queimado depois de estrangulado. Apenas em casos extremos o culpado era queimado vivo - aqueles em que era considerado pertinaz, ou seja, insistente no erro.

A regulamentação dos detalhes procedimentais a serem seguidos era fixada não só pelo procedimento previsto nas Ordenações, mas nos Regimentos da Inquisição. Na época em que o documento ora estudado foi produzido, vigia o Regimento elaborado por ordem do bispo D. Francisco de Castro, então Inquisidor-Geral (1640).

Do ponto de vista jurídico, pode-se dizer que o tipo de processo que englobava a investigação e o julgamento final, na Justiça Eclesiástica, aproxima-se muito do tipo inquisitivo, isto é, aquele em que as funções de acusar, defender e julgar estão todas ligadas a um mesmo órgão - no caso, a Justiça Eclesiástica e o Santo Ofício. Nestes casos, tudo corria em segredo e nenhuma garantia evidente era oferecida ao réu (CINTRA; GRINOVER; DINAMARCO, 1998), o que será verificado mais detalhadamente em item posterior.

\subsection{A denúncia ${ }^{5}$ contra Joana e Lucrécia Gil}

O auto com o registro feito por Gracia (ao que se crê, de forma improvisada, talvez por não haver representação oficial da Justiça Eclesiástica em Mogi Mirim) traz uma denúncia em face de Joana e Lucrécia Gil. A investigação começou ex officio, ou seja, por decisão do Padre Mattos, sem que alguém o solicitasse, fato esse que está registrado no primeiro fólio.

A primeira parte da documentação é composta pela abertura da investigação, com a lavratura do auto, descrição dos fatos e das investigadas. Tudo isso é feito de acordo com a descrição que Manoel Gil fez da proeza da sobrinha.

\footnotetext{
5 Não se sabe com qual conotação foi utilizada a palavra denúncia, tanto aqui como em alguns outros manuscritos objeto da pesquisa. No processo penal brasileiro atual, denúncia é o ato pelo qual o Ministério Público dá início à ação penal, em sequência ao inquérito policial (art. 24, Código de Processo Penal), com caráter investigativo. Porém, nos manuscritos da Cúria em que há situações semelhantes, o que se observa é um procedimento muito semelhante ao do inquérito policial - algo anterior, portanto, ao que hoje se entende por denúncia. Por essa razão, optamos por denominar a sequência de fatos contida no manuscrito relativo a Joana Gil como "investigação", e eventuais menções ao termo "denúncia" e suas derivações ("denunciado", "denunciada" etc.) deverão ser entendidas com essa ressalva.
} 
Em seguida, começam os testemunhos. Seis testemunhas são arroladas - todas do sexo masculino e residentes na cidade. Depois, o Padre Mattos decide pelo envio da documentação a São Paulo, em despacho ${ }^{6}$ específico. Por fım, o escrivão da Sé organiza os autos e os repassa a Manoel Vaz, que determina o envio dos autos ao Santo Ofício. A decisão não é fundamentada ${ }^{7}$, mas, a julgar pela sistemática exposta no item anterior, pressupõe-se que ele, Manoel, tenha reconhecido a existência de fatos suficientes para um julgamento por aquele tribunal.

\section{Qual é o interesse filológico e linguístico nesta documentação?}

Acostumar o olhar do filólogo a documentos de origem judicial pode abrir um novo e vasto campo de investigação. Nesse sentido, os fólios aqui analisados servem como modelo básico de como a documentação judicial manuscrita pode se apresentar ${ }^{\text {. }}$

De início, o que chama a atenção é a identificação do procedimento, das partes envolvidas e de suas fases. No caso em questão, a palavra "auto" está grafada em letras maiores, antecedida pela descrição das partes: de um lado, a Justiça Eclesiástica, que inicia a investigação; de outro lado, Joana e Lucrécia Gil, as investigadas denunciadas. Esta apresentação é necessária para individualizar a documentação e permitir sua localização nos arquivos próprios.

6 Despacho: ato do juiz ou autoridade que dá andamento ao processo ou procedimento, sem possuir, contudo, caráter de decisão (do contrário, seria decisão interlocutória, que decide mas não finaliza o processo, ou sentença, que decide e finaliza o processo) (SIDOU, 2006).

7 A fundamentação das decisões, isto é, a justificativa legal para a tomada de determinada decisão, é dever constitucional imposto ao juiz, atualmente (art. 93, IX da Constituição).

8 Pode haver variações conforme o tipo de procedimento e a época. Até o início do século XX, a identificação do procedimento, por exemplo, era feita de forma manuscrita, com letras pomposas indicando o tipo de procedimento, que era seguido do nome das partes envolvidas. Depois, com a adoção ampla da máquina de escrever, optou-se por padronizar a identificação com uma capa específica. Para exemplos de processos do final do século XIX e início do século XX, v. Fernandes (2012). 


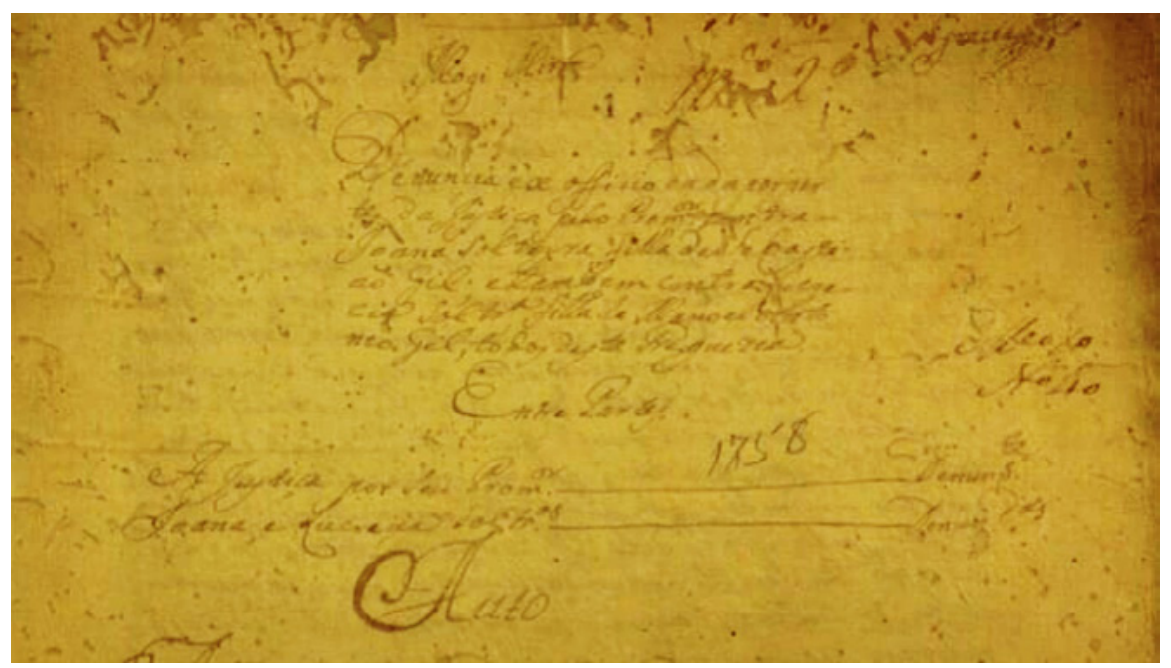

Figura 1. Trecho inicial do manuscrito com a identificação pertinente Fonte: Fólio 1r.

No primeiro parágrafo, indica-se a data de início do procedimento e a cidade, bem como a presença, na abertura do auto, do Padre Mattos e do promotor eclesiástico - papel que, curiosamente, é cumprido por Gracia neste caso. Nestes processos envolvendo a Justiça Eclesiástica, assim como em outros em que há a imbricação entre Igreja e Estado, a indicação da data era sempre feita por meio da fórmula "Anno de Nosso Senhor Jesus Christo de ...", com a data sendo descrita por extenso, começando pelo ano.

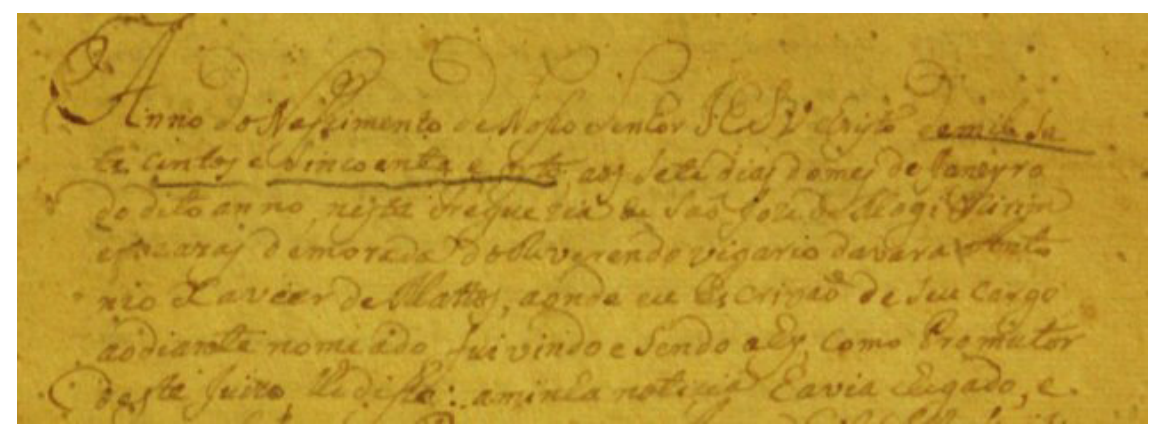

Figura 2. Primeiro parágrafo da abertura da investigação

Fonte: Fólio 1r. 
As diversas fases do procedimento são indicadas por chamadas feitas pelos escrivães - a fala das testemunhas, a abertura de espaço (indicada pelo termo próprio conclusão ${ }^{9}$ ) para os atos específicos da autoridade responsável, como os despachos e decisões. Há também os registros dos atos praticados pelo escrivão em cumprimento às ordens da autoridade, na forma de termos ${ }^{10}$ e certidões ${ }^{11}$.

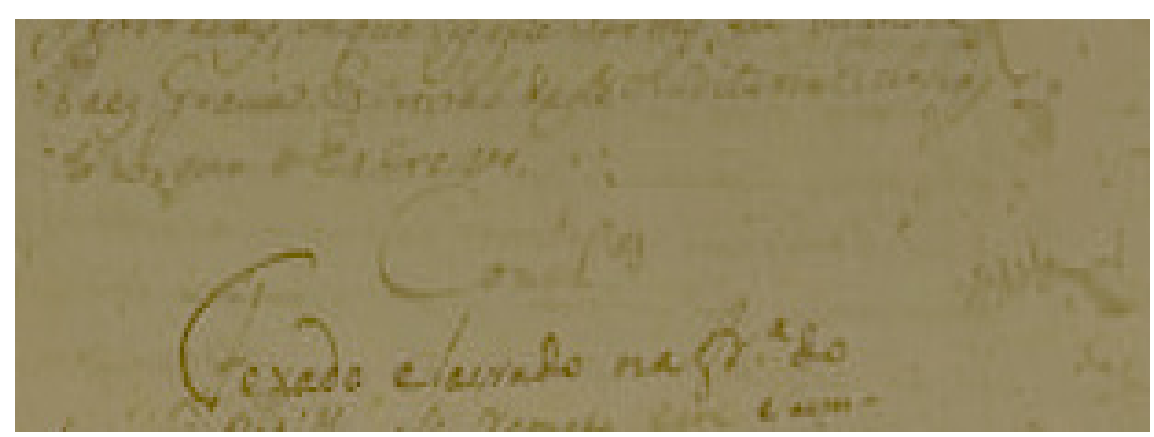

Figura 3. Exemplo de abertura da conclusão (com o termo "conclusos", abreviado para "concl.os", indicando que os autos seguiram a partir daquele ponto para a autoridade)

Fonte: Fólio 12v.

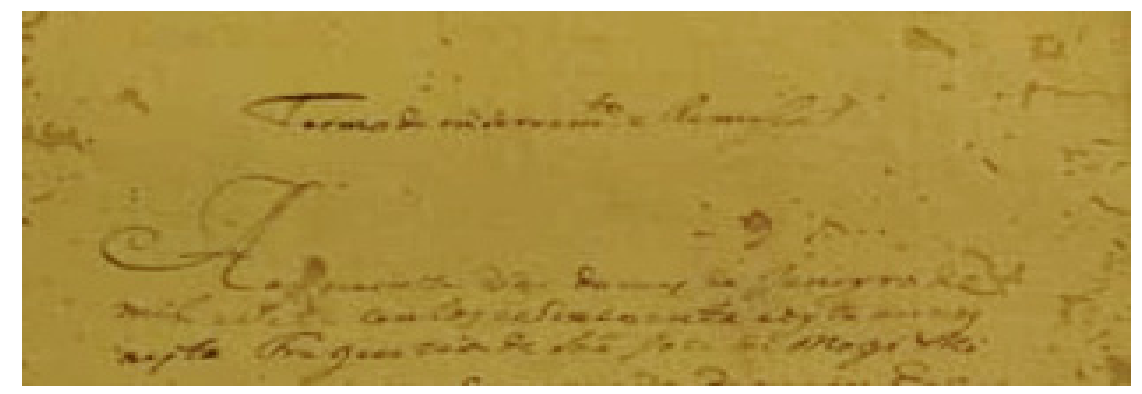

Figura 4. Abertura de termo de encerramento da "denúncia", para envio dos autos a São Paulo

Fonte: Fólio 13r.

9 Conclusão: "denominação do termo pelo qual o escrivão ou secretário do tribunal, conforme o caso, faz remessa dos autos ao juiz, relator ou presidente, para despacho, sentença ou acórdão" (SIDOU, 2016, p. 251). É um indicativo de que a autoridade que preside o processo ou procedimento irá se manifestar.

10 O lexema termo, em direito, é polissêmico. Neste caso, o significado atribuído a ele é o de "instrumento em que são formalizados certos atos processuais" (SIDOU, 2016, p. 1097).

11 Certidão: "Documento pelo qual o servidor público atesta a ocorrência de ato ou fato, ou transcreve qualquer registro, sob sua fé pública, subscrevendo-o" (SIDOU, 2016, p. 198). 


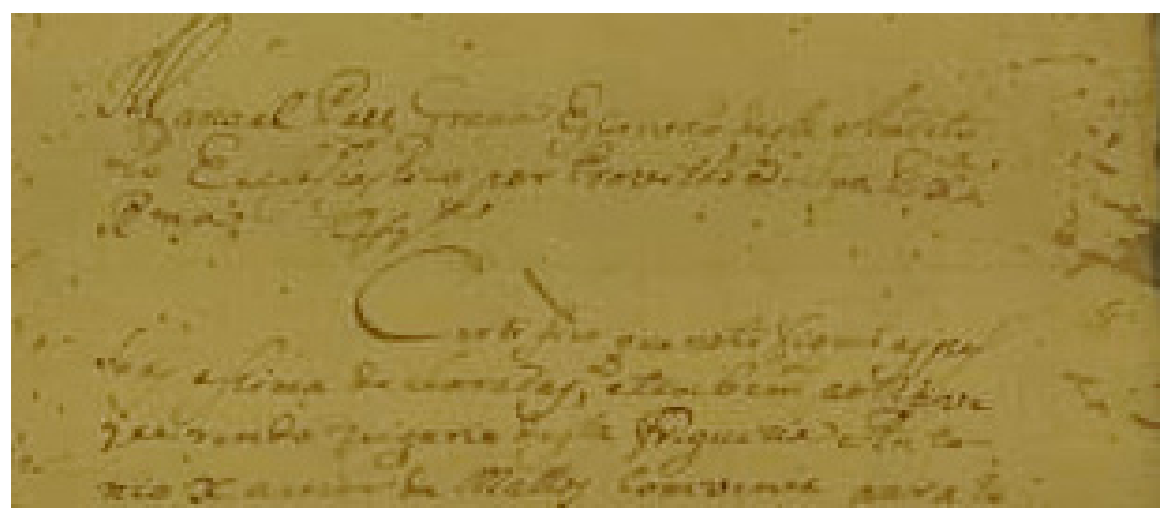

Figura 5. Certidão de notificação das testemunhas (a partir de "Certifico")

Fonte: Fólio 3r.

A terminologia própria pode ser de interesse não só do filólogo, nesse ato de acostumar o olhar para o que é judicial, mas também do linguista, em especial para aquele envolvido com estudos diacrônicos. Chama a atenção o fato de que termos usados no século XVIII sejam usados ainda hoje - e isso ocorre com todos que foram objeto de notas de rodapé explicativas, nos itens anteriores.

Nesta documentação, sobressaem ainda as fórmulas fixas para determinados pontos do texto, também utilizadas até hoje:

a) a qualificação das testemunhas encabeça os manuscritos que registram seus testemunhos, sempre indicada por nome, naturalidade, domicílio, idade e estado civil;

b) após a qualificação, era preciso que as testemunhas jurassem que diriam a verdade, com as mãos sobre um exemplar do Evangelho [dos "Santos Evangelhos", como se vê a cada testemunho que se sucede, tanto nesta documentação como em outras representativas de processos e procedimentos judiciais antes da primeira Constituição da República - v., a respeito, os processos transcritos em FERNANDES (2012)]. Havia determinação legal expressa do Regimento da Inquisição, em seu título 10, a esse respeito;

c) o final de um trecho transcrito pelo escrivão sempre contém a sua identificação mediante a fórmula "eu, [nome do escrivão], escrivão, o escrevi";

d) o encaixe das expressões "ella denunsiada" ou "elle testemunha", conforme o caso, nas orações constantes dos testemunhos, como forma de referência à pessoa que está sendo mencionada na transcrição do escrivão. Este caso é particularmente curioso, pois tem semelhança com hipóteses nas quais o preenchimento do sujeito 
é admitido em línguas de sujeito nulo nas orações subordinadas, mas, ao mesmo tempo, parecem servir como forma de ênfase ou de exclusão de ambiguidade (a respeito da ocorrência de "elle testemunha" em processos dos séculos XIX e XX, v. FERNANDES, 2012, p. 68).

Aliás, tais fórmulas acabavam por forçar a atenção a parâmetros de linguagem considerada culta; e, neste ponto, sobressai também, ainda para fins filológicos e linguísticos, a atuação do escrivão: um profissional da escrita que registrava os diversos acontecimentos nos autos e, especificamente no que diz respeito à tomada de depoimentos e testemunhos, deveria manter os padrões de escrita em situações de pressão, em que deveria escrever de forma rápida e eficiente. É possível que a criação das fórmulas visasse justamente a manutenção de um padrão de escrita - o que não impedia que, em função da pressão que mencionamos, registrasse marcas de oralidade ${ }^{12}$.

\section{Interesse para o direito (e, mais particularmente, para a história do direito)}

O fato de São Paulo possuir documentação relacionada à Justiça Eclesiástica e à Inquisição já seria, por si mesmo, relevante para instigar também o pesquisador do Direito a adentrar os documentos do fundo da Cúria. Nesse sentido, o trabalho de transcrever e organizar o material, do ponto de vista filológico, pode servir como suporte a esse tipo de pesquisa.

Mas, pela análise dos documentos citados neste estudo, podemos verificar também discrepâncias entre o ordenamento jurídico então vigente e o que se apresenta hoje, o que traz mais elementos que podem justificar uma interação interdisciplinar entre a filologia e a história do direito.

Essa interação poderia revelar comparações inevitáveis com a ordem jurídica então vigente e a atual, ou mesmo entre esses manuscritos da Justiça Eclesiástica e outros já estudados.

Como exemplo, podemos citar a circunstância já destacada no item 3.1, sobre o processo junto ao Santo Ofício ter características do tipo inquisitivo. Isso se mostra, em primeiro momento, quando se destaca que, na investigação ora em análise, Joana e Lucrécia não foram ouvidas em nenhum momento. Tudo o que sabemos dos fatos vem das testemunhas - todas, como vimos, homens e sem proximidade com as moças, à exceção de Manoel Gil.

12 Verifica-se esse tipo de ocorrência, com clareza, ao longo de Fernandes (2015). 
A garantia de que a pessoa alvo da denúncia será ouvida faz parte, hoje, do princípio do contraditório e da ampla defesa (consolidado, na atual Constituição brasileira, em seu art. $5^{\circ}{ }^{\circ}$, inciso LV), o qual assegura que essa pessoa poderá fornecer a sua visão dos fatos e se manifestar contraditando aquilo com o que não concorda - motivo pelo qual deve ser notificada de todos os atos praticados e realizar as provas que requereu (cf. NERY JUNIOR, 2010).

Outra ofensa a esse princípio é o fato de Manoel Paez Gracia ter aberto a denúncia a pedido do Padre Mattos, sem ficar claro se tinha o cargo de promotor eclesiástico de forma oficial (mas, mesmo assim, chega a assinar como tal, acumulando os papéis de escrivão e promotor). Dessa forma, como escrivão e promotor, pode ter atuação suspeita no registro dos testemunhos, uma vez que pode anotar o que bem entender, de forma a favorecer a posição contrária a Joana e Lucrécia.

Dessa forma, se Joana e Lucrécia já não tinham voz no processo, mais difícil ainda fica sua defesa, já que não há garantias de que Gracia tenha registrado os testemunhos de forma fidedigna.

Ainda, o próprio testemunho do Padre Mattos é, no mínimo, bizarro para os padrões atuais, já que é o juiz eclesiástico incumbido da verificação dos fatos e, ao mesmo tempo, presta seu testemunho - neste caso, a se considerar o direito atual (art. 252, II do Código de Processo Penal), configura-se a hipótese de impedimento, prevista justamente para evitar que a situação seja conduzida de forma unilateral (resguardando-se, mais uma vez, a garantia de contraditório e ampla defesa às denunciadas); nem ao menos se permite prova em contrário (v. a respeito NERY JUNIOR, 2010).

Afınal, o juiz/autoridade responsável precisa ser imparcial, para que se possa efetivamente dar uma solução equilibrada à questão que é posta em causa. Cabe ressaltar que o direito a um juiz imparcial é previsto na Declaração Universal dos Direitos Humanos de 1948.

Por fim, mais uma característica de processo inquisitivo se verifica quando os autos da investigação são remetidos em segredo para São Paulo e depois para o Santo Ofício, o que também se choca com a estrutura atualmente vigente. A publicidade dos atos processuais é outra garantia constitucional de que as partes envolvidas serão julgadas com a devida isenção, e vem prevista nos arts. $5^{\circ}$, LX e 93, IX da Constituição. Atualmente, são poucas as hipóteses de trâmite em segredo, restritas a situações em que há risco de que a publicidade afete o correr do feito.

A partir do exposto, nota-se que o pesquisador da história do direito, com análise aprofundada do material facilitada pela filologia, pode extrair novas e ricas possibilidades para, talvez, escrever mais um capítulo, vinculado não só à questão da Justiça Eclesiástica mas também ao direito colonial, de modo amplo. 


\section{Conclusão}

Este é apenas um exemplo dentre os demais documentos que fazem parte do projeto Bruxas Paulistas. Mas, por meio dele, pode-se ter uma ideia do panorama do andamento do trabalho e do que tem sido possível descobrir e explorar.

As particularidades apresentadas acima, relacionadas à investigação de Joana e Lucrécia Gil, permitem entrever a riqueza de detalhes contida na documentação da Cúria Metropolitana de São Paulo, no que diz respeito aos processos e investigações sobre crimes contra a Igreja.

Não há dúvida de que a exploração pode, de fato, abranger diversas frentes - no caso, a filologia, a linguística e a história do direito. Pode-se dizer ainda mais: as três disciplinas poderão interagir entre si, criando um núcleo de pesquisa interdisciplinar.

Isso ficou mais evidente nos itens 3 e 4, nos quais, a partir das ferramentas da filologia, os conceitos jurídicos permitiram a compreensão plena do conteúdo do manuscrito, trazendo à tona peculiaridades linguísticas, do ponto de vista (i) lexicográfico, contido na terminologia jurídica, (ii) sociolinguístico, considerando-se as fórmulas específicas de uma linguagem relacionada a uma área de atuação, (iii) sintático, a partir das indagações sobre as estruturas "ella denunsiada" ou "elle testemunha"; (iv) diacrônico, a partir da constatação de que muitas estruturas (especialmente lexemas) ainda fazem parte da linguagem jurídica atual.

A continuação dos trabalhos pode eventualmente abrir novas possibilidades ainda mais expansivas para a exploração dos manuscritos do século XVIII, da questão da Justiça Eclesiástica no Estado de São Paulo e do direito colonial.

\section{REFERÊNCIAS}

ALMEIDA, C. M. de. Ordenações Filipinas: Código Phillipino ou Ordenações e Leis do Reino de Portugal. v. 3, Livros IV e V. Rio de Janeiro: Typographia do Instituto Philomatico, 1870.

BRASIL. Código de Processo Penal. Decreto-Lei 3.689, de 03.10.1941. Disponível em: http://www.planalto.gov.br/ccivil_03/decreto-lei/del3689.htm. Acesso em: 12 jul. 2019.

BRASIL. Constituição Federal de 1988. Disponível em: http://www.planalto.gov.br/ ccivil_03/constituicao/constituicao.htm. Acesso em 12 jul. 2019.

CAMBRAIA, C. N. Introdução à crítica textual. São Paulo: Martins Fontes, 2005. 
CINTRA, A. C. A.; GRINOVER, A. P.; DINAMARCO, C. R. Teoria geral do processo. 14. ed. São Paulo: Malheiros, 1998.

FERNANDES, N. F. Documentação judicial: o depoimento. São Paulo: FFLCH-USP, 2015 (Arquivos do NEHILP, v. 8).

FERNANDES, N. F. Sujeito nulo na história do português de São Paulo: 1878-1948. 2012. Dissertação (Mestrado em Filologia e Língua Portuguesa) - Faculdade de Filosofia, Letras e Ciências Humanas, Universidade de São Paulo, São Paulo, 2012.

NERY JUNIOR, N. Princípios do processo na Constituição Federal. 10. ed. São Paulo: Revista dos Tribunais, 2010.

PORTO, N. P. Feitiçaria paulista: transcrição de processo-crime da Justiça Eclesiástica na América portuguesa do século XVIII. 2018. Dissertação (Mestrado em Filologia e Língua Portuguesa) - Faculdade de Filosofia, Letras e Ciências Humanas, Universidade de São Paulo, São Paulo, 2018.

PORTUGAL. Regimento do Santo Ofício da Inquisição dos Reinos de Portugal. Disponível em: https://digitarq.arquivos.pt/viewer?id=2318864. Acesso em: 12 jul. 2019.

SIDOU, J. O. Dicionário jurídico. 11. ed. Rio de Janeiro: Forense, 2016.

TUCCI, J. R. C.; AZEVEDO, L. C. de. Lições de história do processo civil lusitano. São Paulo: Revista dos Tribunais, 2009. 